\title{
Participar por que e para que? O que dizem os usuários finais de Tecnologia Assistiva
}

\section{Resumo}

Este trabalho visa apontar possíveis relações entre os estudos que indicam a necessidade de educação para o usuário final de Tecnologia Assistiva e o modelo social da deficiência. Desejamos contribuir com possíveis aspectos que explicitam a importância das "vozes" das pessoas com deficiência no processo de escolha e uso de recursos e serviços de Tecnologia Assistiva, visto que são esses os conhecedores das reais necessidades vivenciadas pela experiência da deficiência. Buscando melhor elucidar a relevância das "vozes" das pessoas com deficiência em relação à temática, convidamos sete pessoas usuárias de Tecnologia Assistiva, para responderem um questionário on-line, as respostas foram submetidas a análise textual discursiva. As narrativas apontaram que a educação do usuário deve ser considerada o elemento mais importante para que possam ser protagonistas de todo o processo, desde a identificação da necessidade até o uso do recurso ou do serviço de Tecnologia Assistiva.

Palavras-chave: Tecnologia Assistiva; Usuários Finais; Educação; Modelo Social da deficiência.

\section{Participate why and for what?}

\section{What the end-users of Assistive Technology say about}

Abstract

This work aims to identify possible relationships between studies that indicate the need for education to the end user of Assistive Technology and the social model of disability. We wish to contribute to possible aspects that explain the importance of the "voices" of people with disabilities in the process of selection and use of Assistive Technology resources and services, because they are who really know about the needs experienced by the experience of disability. Seeking to further elucidate the relevance of the "voices" of people with disabilities in relation to the theme, we invite seven people who use Assistive Technology, to answer an online questionnaire, the answers were submitted to discourse textual analysis. The narratives indicated that user education should be considered the most important element for them to be protagonists of the entire process, from identification of the need to use the facility or Assistive Technology Service.

Key-Words: Assistive Technology; End Users; Education; Social Model of Disability.

\footnotetext{
${ }^{1}$ Professora do Instituto Federal de Santa Catarina - Campus Araranguá. Doutoranda do Programa de Pós- Graduação em Educação Científica e Tecnológica - UFSC.
} 


\section{Introdução}

Este trabalho visa apontar possíveis relações entre o processo de educação para $o$ usuário final de Tecnologia Assistiva e a perspectiva do modelo social da deficiência. Desejamos contribuir com aspectos que explicitem a importância das "vozes" das pessoas com deficiência no processo de escolha e uso de recursos e serviços de Tecnologia Assistiva, visto que são esses os conhecedores das reais necessidades vivenciadas pela experiência da deficiência.

Embasaremos este trabalho nos estudos dos autores Diniz (2003, 2007), Palacios (2008) e Martins et al (2012), e para a Tecnologia Assistiva nos apoiaremos em autores como Bersch (2006, 2009), Galvão Filho $(2009,2013)$ assim como os documentos Educação em Tecnologias de Apoio para utilizadores finais e o Manual para usuários de Tecnologia da reabilitação desenvolvidos pelo Empowering Users Through Assistive Technology - EUSTAT (1999).

Os autores das pesquisas elencadas para esta discussão abordam sobre a importância da formação educacional para o usuário final que vai desde a escolha e se estende para o uso da Tecnologia Assistiva. Reconhecemos que para este aspecto ser cada vez mais considerado, fazse necessário que a pessoa com deficiência seja o foco de todo este processo, que deve destacar a necessidade de capacitação para que estes usuários tornem-se conhecedores da temática e parceiros dos profissionais e familiares ${ }^{1}$.

Corroboramos com os autores apresentados, quando referem que é o usuário o mais indicado a falar acerca das reais necessidades e particularidades, já que ainda vivem numa sociedade que se apresenta com muitas barreiras arquitetônicas, atitudinais e políticas. Pensando nisso, foi de extrema relevância a participação de usuários de Tecnologia Assistiva nesta pesquisa. As narrativas registradas no questionário on-line, enviado pela pesquisadora, contribuíram com a análise. Nota-se que quando falamos em participação do usuário não deveria haver situações de encaminhamento para o uso da referida tecnologia sem que estes usuários sejam protagonistas de todo o processo desde a identificação de sua necessidade até o uso do recurso ou do serviço propriamente dito.

Embora algumas pesquisas já tenham apontado contribuições neste sentido, infelizmente o modelo biomédico da deficiência parece ser o olhar que prevalece sobre as ações e intervenções dos profissionais da saúde, da educação e da população em geral. As pessoas com deficiência são entendidas como aquelas que "carregam o pesado fardo da tragédia pessoal" e que necessariamente precisam da ajuda dos outros para ser e estar no mundo, sendo assim, considerados incapazes de poder contribuir no processo de escolha, customização e/ou uso de recursos e serviços de Tecnologia Assistiva.

Apontamos que os estudos sociais da deficiência e os documentos que evidenciam a necessidade de educação para os usuários finais podem contribuir para amenizar a visão assistencialista e piedosa que a pessoa com deficiência ainda se depara em vários segmentos sociais, assim como, colaborar para que imperativas mudanças na área de TA sejam alcançadas por todos aqueles que dela possam se beneficiar.

\section{Tecnologia Assistiva: perspectivas históricas e debates conceituais}

De acordo com Bersch (2005), o surgimento das primeiras tecnologias assistivas pode ter origem na pré-história. Dizem que pode estar ligado ao fato de o ser humano pré-histórico ter feito uma bengala com um galho de árvore após ter fraturado a perna para poder seguir caminhada com o grupo.

Embora possam ter sua origem surgida nos primórdios da humanidade o termo só foi estabelecido mais tarde. Serão apresentadas neste artigo duas versões quanto à terminologia encontradas na literatura: a primeira descrita por John M. Williams e a segunda publicada por Bersch (2005).

O jornalista, John M. Willims, foi personagem de uma história bastante incomum para os dias de hoje. Porém, na época as escolas não estavam preparadas e nem aceitavam o "diferente". Williams, conta que quando era criança e começou a escrever, percebeu que era canhoto. Parece comum, mas na época por volta dos anos 1950 isso era considerado errado e a escola não aceitava. A professora, então, seguindo os parâmetros vigentes, amarrava sua mão 
esquerda, fazia-o sentar sobre ela a fim de conseguir treinar o aluno a utilizar a mão direita como seus colegas, porém, Williams tinha grande dificuldade. Então, no dia 14 de fevereiro de 1954, os alunos receberam uma tarefa da professora do segundo ano. Williams começou a fazêla, porém utilizando sua mão esquerda, quando a professora com uma régua metálica, batendo, quebrou-lhe o pulso e os dedos. Devido a esse episódio, Williams adquiriu limitações motoras em sua mão e gagueira, que possivelmente estava relacionada ao episódio que o marcara profundamente.

A limitação não impediu de seguir seus estudos e conquistar uma carreira. Durante toda sua vida profissional como escritor, John M. Williams procurou escrever sobre tecnologias, materiais e equipamentos que facilitavam a vida das pessoas com deficiência. Willians já havia perdido diversas oportunidades de emprego, de namoro e até mesmo de fazer coisas comuns, devido ao grau elevado na gagueira, o que o impedia de se comunicar fluentemente. Várias vezes fora dispensado embora tivesse notas excelentes.

Então, em 1970, Willians aceitando a indicação do amigo, resolveu participar dos trabalhos com o Dr. Jim Hillis. Depois de meses fazendo as atividades do programa que usava um robô para ajudar a pessoa a perceber a gagueira e suas limitações, William deixou de sentir vergonha de si e já conseguia expressar-se publicamente. Era constantemente convidado a proferir relatos sobre o uso da tecnologia. Muitas pessoas com deficiência o procuravam para contar suas histórias e ele as publicava. Em 1982, ao escrever uma de suas histórias no Washington Post, William definiu e nomeou pela primeira vez o termo Tecnologia Assistiva. Ele desejou dar nome a todos aqueles equipamentos, mas não sabia como. Pensou em "alternativas" e chegou a expressão "assistência" e resolveu encurtar facilitando seu uso, chegando assim ao termo Assistiva.

A outra versão acerca da definição deste termo foi publicada por Bersch (2005). Segundo a autora esse termo só tornou-se oficial com a Public Law 100-407, em 1988, nos Estados Unidos da América.

Indiferente da versão, o que desejamos expor com estas histórias é o quão importante a Tecnologia Assistiva pode vir a ser para a vida da pessoa com deficiência, em especial, se ela for o centro do processo. Embora, entendemos que muitas vezes o acesso aos recursos e serviços de Tecnologia Assistiva é difícil para as pessoas com deficiência. E quando tem acesso, muitas vezes o desconhecimento dos profissionais impossibilita a participação do usuário no processo desde a escolha até o uso final.

Diante disso entendemos que Tecnologia Assistiva ${ }^{2}$ por si não basta, é preciso que elas sejam compreendidas e bem utilizadas para que se tornem efetivas nas suas funções. Portanto, entender o conceito e os recursos que são parte da conceituação e o que abrange se faz necessário para todos os setores da sociedade.

Podemos perceber que a conceituação, terminologia utilizada nos diferentes lugares do mundo é bastante polissêmica. Saber quais são essas diferenças, quais os recursos e os serviços que fazem parte das definições nos diferentes países, pode nos possibilitar entender melhor o estudo elaborado pelo Comitê de Ajuda Técnica no Brasil (2007) para chegarem a definição hoje utilizada em nosso país.

Nos Estados Unidos da América a TA se consolidou em 1988 com a aprovação da Public Law 100-407 ou Lei Tech, assegurando deste modo os direitos de acesso e adaptações razoáveis, como também o direito de receber os recursos por meio do poder público. Outro aspecto relevante dessa lei foi a definição e distinção entre os termos recursos e serviços. Recursos definiu-se como "todo e qualquer item, equipamento ou parte dele, produto ou sistema fabricado em série ou sob-medida, utilizado para aumentar, manter ou melhorar as capacidades funcionais dessa pessoa" e Serviços, "aqueles que auxiliam diretamente uma pessoa com deficiência a selecionar, comprar ou usar os recursos definidos" (BERSCH, 2006, p.3).

Embasados nessa legislação os autores Cook e Hussey definem Tecnologia Assistiva como "uma ampla gama de equipamentos, serviços, estratégias e práticas concebidas e aplicadas para minorar os problemas funcionais encontrados pelos indivíduos com deficiências" (GALVÃO FILHO, 2009, p.130). Esses autores conseguem expor a definição de TA como algo 
para além da concepção instrumentalista em que tecnologia estaria ligada apenas à máquina e equipamentos.

Aspectos semelhantes percebem-se no âmbito europeu.

Para a Empowering Users Through Assistive Tecnologies (EUSTAT) uma questão bastante relevante está em capacitar e conscientizar as pessoas com deficiência para optarem por um estilo de vida mais independente, podendo optar pela TA que melhor lhes servir e que permita maior amplitude de funções. Pautados nessa premissa, definem o termo como tecnologia de apoio, explicam que:

Em primeiro lugar, o termo tecnologia não indica apenas objectos físicos, como dispositivos ou equipamento, mas antes se refere mais genericamente a produtos, contextos organizacionais ou "modos de agir" que encerram uma série de princípios e componentes técnicos. [...] Em segundo lugar, o termo de apoio é aplicado a uma tecnologia, quando a mesma é utilizada para compensar uma limitação funcional, facilitar um modo de vida independente e ajudar os idosos e pessoas com deficiência a concretizarem todas as suas potencialidades. Algumas destas tecnologias, se bem que não especificamente concebidas para pessoas com deficiência, podem ser ajustadas por forma a preencherem a função de apoio, quando necessário (EUSTAT, 1999a, p 15).

A EUSTAT desenvolveu um programa de capacitação sobre as tecnologias, que teve aspectos relevantes, um deles: fazer com que a pessoa deficiente torne-se sujeito ativo nas escolhas. Tal capacitação foi denominada de controle direto feito pelo usuário final de tecnologia de apoio. Galvão Filho (2009) explica que o objetivo da capacitação ofertada pela EUSTAT para usuários de TA, familiares e profissionais é que "os mesmos pudessem fazer escolhas informadas, adequadas e responsáveis em relação a essas tecnologias. Esse estudo parte do princípio de que é fundamental a participação de usuário final como parceiro ativo na escolha das Tecnologias de Apoio que utiliza" (GALVÃO FILHO, 2009, p. 131).

A EUSTAT, escolheu a Classification Horizontal European Activities in Rehabilitation Technology - HEART, a fim de orientar os países e instituições membros. Esta classificação entende que um indivíduo será mais ou menos deficiente, em termos de funcionalidade e participação, quanto mais ou menos deficiente ou acessível for o seu ambiente, aspecto este, que entendemos estar em consonância com o modelo social. Portanto, é possível entender que as modificações devem ocorrer, especialmente, na sociedade.

É importante destacar ainda que esta classificação HEART foi desenvolvida com o objetivo de formação para profissionais em Tecnologia Assistiva, por isso sofreu algumas adaptações com o objetivo de se adequar com os objetivos da EUSTAT, em especial, para que deixasse o usuário como foco do processo. A HEART é uma classificação que trata de reabilitação e define as tecnologias como de reabilitação, elas são amplas e englobam serviços e práticas.

A Classificação Internacional da Funcionalidade, Incapacidade e Saúde - CIF também é uma importante classificação com múltiplas finalidades elaborada para servir a várias disciplinas e setores. Utiliza o termo Tecnologia de Assistência que compõe o item Fatores Ambientais, o mesmo diz respeito ao ambiente físico, social e atitudinal em que vivem as pessoas com deficiência. Conceitua Tecnologia de Assistência como "qualquer produto, instrumento, equipamento ou tecnologia adaptado ou especialmente concebido para melhorar a funcionalidade de uma pessoa com incapacidade" (CIF, 2001, p. 140).

Apresentamos ainda, a International Organization for Standartization ISO 9999/2011. É a mais recente classificação internacional acerca da temática, define produtos de assistência. A definição utilizada por esta norma internacional foi revisada para alinhá-la com a terminologia da Classificação Internacional de Funcionalidade, Incapacidade e Saúde, citada no parágrafo acima (ISO 9999, p. v, 2011). 
Este mapeamento das diferentes conceituações e terminologias proporcionou ao Comitê de Ajudas Técnicas conceituar o termo no Brasil. Tal comitê, criado pela portaria número 142 de 16 de novembro de 2006, foi de grande relevância para os estudos da Tecnologia Assistiva no país. Esse definiu que Tecnologia Assistiva é

Uma área do conhecimento, de característica interdisciplinar, que engloba produtos, recursos, metodologias, estratégias, práticas e serviços que objetivam promover a funcionalidade, relacionada à atividade e participação, de pessoas com deficiência, incapacidades ou mobilidade reduzida, visando sua autonomia, independência, qualidade de vida e inclusão social (BRASIL, 2008, p. 3).

A conceituação brasileira permite que entendamos que esta tecnologia está para além de máquinas e recursos. Este conceito permite a abertura para uma possível reflexão e discussão acerca da educação para o usuário final como elemento imprescindível, aspecto este que precisa ser cada vez mais incorporado nos serviços de TA por todos os profissionais que trabalham com a referida tecnologia.

\section{Percurso metodológico: a participação do usuário de Tecnologia Assistiva para a pesquisa}

Esta pesquisa foi de cunho qualitativo e buscou a participação de pessoas com deficiência usuárias de Tecnologia Assistiva. As expressões dos participantes foram submetidas a análise textual discursiva que segue três etapas: desmontagem dos textos (unitarização), categorização e a construção de metatextos (comunicação).

A primeira, a unitarização é uma etapa que possibilita ao pesquisador uma incursão no corpus da pesquisa. São as vozes das pessoas participantes da pesquisa que podem ser vistas como produções que expressam discursos sobre os diferentes fenômenos e que podem ser lidos, descritos e interpretados correspondendo a uma multiplicidade de sentidos que a partir deles podem ser construídos. A categorização é aquela em que o pesquisador precisa definir as categorias de análise de sua pesquisa. Por fim, a análise textual discursiva leva o pesquisador a atuar de forma coerente e se colocando como autor de seus escritos, articulando-os com teorias prévias e dando a possibilidade de se criarem novas teorias.

Para podermos viabilizar a realização desta análise, reiteramos ser necessário convidar usuários de Tecnologia Assistiva para que de alguma forma pudessem expressar o processo vivido na escolha e uso dos recursos e serviços. Assim, resolvemos convidar algumas pessoas com deficiência.

No início, levantamos cinco nomes que compunham um grupo de alunos de uma disciplina de um curso de pós-graduação, todos foram contatados via e-mail, e convidados a responderem um questionário com cinco questões. Acompanhando o convite, um termo livre e esclarecido de participação e uso das respostas dadas apenas para este trabalho.

Dos participantes que receberam o convite e o questionário, três contribuíram com a pesquisa, um respondeu o e-mail explicando seus motivos para não responder o questionário e outros dois não sinalizaram recebimento do mesmo. Porém, um dos participantes convidou outros dois para responderem o questionário, e desses, um envio o questionário respondido.

Sendo, assim das sete pessoas convidadas, quatro responderam ao questionário.

As mesmas serão denominadas pelas siglas Q1, Q2, Q3, Q4. Os participantes são de ambos os sexos: masculino (1) e feminino (3), a faixa etária variou entre 23 e 32 anos, uma das pessoas não declarou sua idade. Todos possuem ensino superior completo, e três declararam ser estudantes de pós-graduação. Dois declararam ser usuários de Tecnologia Assistiva desde a infância e dois relataram que iniciaram o uso na fase adulta.

Caiado (2003) explica a importância de ouvir as pessoas com deficiência quando sobre elas vamos escrever: 
Nesse sentido, aqui se busca conhecer o que eles [...] têm a contar sobre suas vidas, suas experiências, seus anseios; quais as lembranças que carregam [...] (CAIADO, 2003, p. 44).

Sendo assim, entendemos que não poderíamos falar sobre a participação do usuário de Tecnologia Assistiva se suas vozes não fossem as protagonistas da análise proposta.

\section{O que dizem os usuários? Uma análise acerca das narrativas dos usuários de Tecnologia Assistiva}

O modelo social da deficiência surgiu em 1970, na perspectiva contrária ao modelo biomédico. Desta forma, deficiência deixa de ser uma anormalidade pertencente unicamente ao corpo. Assim deficiência

[...] não é mais uma simples expressão de uma lesão que impõe restrições à participação social de uma pessoa. Deficiência é um conceito complexo que reconhece o corpo com lesão, mas que também denuncia a estrutura social que oprime a pessoa deficiente [...] desvantagem ou restrição de atividade provocada pela organização social contemporânea, que pouco ou nada considera aqueles que possuem lesões físicas e os exclui das principais atividades da vida social (DINIZ, 2007, p. 9 e 17).

Nesta perspectiva, o modelo social não ignora o fato de que a pessoa com deficiência tem uma lesão medular e que em muitos casos necessita de reabilitação e tratamento médico, assim como, também não desconsidera a relevância que a Tecnologia Assistiva possa ter na vida desses usuários. Ao contrário defende a participação ativa das pessoas com deficiência, incluindo nestas a possibilidade de ter conhecimento para participar das escolhas e reflexões acerca da TA para suas vidas. Não queremos com isso dizer que a Tecnologia Assistiva torna-se responsável ou a única possibilidade destes usuários para realizarem ações cotidianas, educacionais e laborais, pois não acreditamos na visão instrumentalista ${ }^{3}$, mas sim que possa ser um elemento que possibilite autonomia e qualidade de vida, em especial, destacamos a comunicação e a estabelecimento de relações sociais.

Neste trabalho, procuramos deixar expresso nosso entendimento e olhar para a pessoa com deficiência, afiliando-se a perspectiva do modelo social. Sendo assim, torna-se inaceitável, que tais pessoas não sejam o foco da pesquisa. Por meio de narrativas podemos explicitar algumas das necessidades que os participantes dizem enfrentar na sociedade que se alicerça em bases segregatórias e excludentes, as quais muitas vezes podem/poderiam ser minimizadas com o acesso e uso de recursos de Tecnologia Assistiva.

Então, compartilhamos que a Tecnologia Assistiva pode se constituir num importante elemento na e para a conquista da independência, autonomia e qualidade de vida para a pessoa com deficiência, proporcionando participação social em condições de igualdade. Bem como, o modelo social da deficiência pode ser entendido como uma luta social e política criada e mantida por essas pessoas, em contradição ao modelo que desejava cuidar, esconder e segregar, como o realizado por instituições especializadas, embora algumas sejam marcos históricos importantes. Desta forma, parece evidenciar-se a relação estreita entre o indicativo de educação para o usuário de Tecnologia Assistiva e o modelo social da deficiência.

A história de John Williams que abordamos na primeira seção deste trabalho, parece assemelhar-se em muitos aspectos com a definição de deficiência expressa por Diniz (2007). Em virtude das condições provocadas - pela professora - foi excluído da sociedade, e após realizar serviço de reabilitação e encontrar a Tecnologia Assistiva que melhor se adequava as suas necessidades, conquistou independência e autonomia na vida.

Assim como Williams, os participantes desta pesquisa expuseram através das narrativas as diferentes relações que estabeleceram com os recursos e serviços a que tiveram acesso durante suas vidas. 
Podemos apontar, pelas respostas dadas pelos participantes, que no período da infância as escolhas em relação ao tipo de recurso e serviço de Tecnologia Assistiva eram feitas pelas famílias e ou profissionais da saúde e educacionais. Sobre isso o participante denominado Q3 relatou:

Como maior parte [escolhas] foi quando criança, acredito que a escolha passava pelos professores e meus pais, como exemplo, utilizei livros didáticos em braille até a oitava série, sendo que sempre tive dificuldade para leitura braille. Após iniciei um maior uso do computador e passei a ler materiais de estudo de forma digital, o que mudou minha vida escolar (Q3).

O trecho expresso é bastante relevante, pois se nos afiliamos a forma de "ver" a pessoa com deficiência expressada pelo modelo social, compartilhamos com a ideia de que desde a infância deveria ser direito destas a decisão e as escolhas sobre seu corpo e a forma como vai estar no mundo. De acordo com Palacios (2008), apoiada nas ideias de Oliver, a escola pode ser uma instituição muito importante na preparação das pessoas para a participação na sociedade, bem como, seria esta instituição também responsável por propor conhecimentos acerca dos direitos e deveres dos cidadãos, para que estes pudessem alcançar uma vida adulta e independente. Porém, percebe-se que isso não ocorre em muitos casos nem na fase adulta, em especial, nos casos mais graves de deficiência, especialmente, em casos onde a pessoa não se expressa verbalmente.

A EUSTAT, como já expresso anteriormente, destaca-se em suas linhas de capacitação por colocar o usuário como o gestor das suas escolhas. Tal ideia fica explícita quando apresenta no Manual Educação em tecnologias de apoio para utilizadores finais: linhas de orientação para formadores (1999a) as vertentes sociais e tecnológicas focadas na auto formação do usuário final:

[...] partindo da noção de que as pessoas com deficiência deveriam ser capacitadas para participarem como principais intervenientes $\mathrm{e}$ parceiros activos no processo decisório sobre TA, considerou-se que a transferência de conhecimentos para os utilizadores finais poderia promover a igualdade de oportunidades, introduzir um controlo directo dos consumidores sobre a qualidade dos serviços e produtos das TA e melhorar a eficácia de utilização destas técnicas (EUSTAT, 1999a, p. 8).

Assim, torna-se de fato necessário que os usuários sejam parceiros responsáveis e capacitados sobre o assunto, a fim de entender o que querem, o que desejam, o que esperam e quais as reais necessidades em relação aos recursos e serviços de Tecnologia Assistiva que buscam. Caso contrário, corre-se o risco de escolhermos/escolherem recursos que não contemplam tais aspectos e com isso a possibilidade de que esses recursos entrem em desuso torna-se expressiva. A participante Q1 narrou em seu questionário que não participou da escolha da cadeira de rodas que faz uso na universidade em que estuda, e que quando a mesma foi entregue a ela, não contemplava as especificidades corporais "era uma cadeira para quem tem a possibilidade de empurrar as rodas" (Q1). Completou dizendo:

Acredito que faz toda a diferença ouvir a pessoa que utilizará o recurso e o serviço de Tecnologia Assistiva. É como comprar um presente: quanto mais você conhece a pessoa, menos chance haverá de ela precisar trocá-lo. Se a pessoa com deficiência for ouvida em relação às suas necessidades, maior a chance de acertarem os recursos. Caso contrário, gasta-se tempo, energia e verba desnecessariamente (Q1).

Sobre este mesmo aspecto a participante Q4 expressou:

A definição dos produtos que uso se dão por profissionais a partir de minhas descrições e dos resultados obtidos pelas análises computadorizadas referentes aos efeitos dos produtos durante o uso no teste (Q4). 
Outro aspecto que se pode perceber nas narrativas dos participantes que declararam usar Tecnologia Assistiva desde a infância, é que suas escolhas passaram a ser mais respeitadas na fase da adolescência.

Minhas escolhas se tornaram mais importantes na adolescência onde eu tive oportunidade de conhecer mais tecnologias e mais consciência que eu deveria ter essa oportunidade de escolha (Q3).

Um dos recursos que utilizo, o teclado virtual do Windows, descobri ainda na adolescência juntamente com minha família mexendo no computador (Q2).

Com base nos questionários, ainda foi possível evidenciar o quão necessária é a divulgação dessa temática para todos os profissionais, familiares e, em especial, os próprios usuários. Tudo isso pode contribuir para uma possível alteração na forma que vem ocorrendo a oferta de recursos e serviços de Tecnologia Assistiva pelos órgãos públicos e privados. Destacase neste processo a necessidade de mudança na aquisição dos recursos pelos próprios usuários, pois cada vez mais os usuários precisam passar por capacitações, processos de educação sobre seus direitos, deveres, necessidades e particularidades da sua deficiência para que possam falar por si e com isso refletir acerca do significado da TA no contexto da vida humana e para suas próprias vidas.

Sendo assim, acreditamos ser a perspectiva defendida pelo modelo social um importante argumento para que as "vozes" das pessoas com deficiência estejam, permanentemente, no centro de qualquer escolha.

\section{Considerações Finais}

Todos os recursos e serviços de Tecnologia Assistiva que tive acesso até hoje sempre tive participação total, tanto na escolha dos profissionais quanto na compra ou confecção dos recursos. A terapeuta ocupacional sempre me ouviu e partindo das minhas necessidades e conhecimentos dela, os recursos que utilizo foram criados, pois a maioria dos que existem no mercado não se adaptam as minhas necessidades.

Acredito que a participação do usuário no processo é de fundamental importância, pois é necessário se partir da necessidade e limitações de cada pessoa que nunca será igual a da outra, mesmo tendo a mesma deficiência $(Q 1)$.

Escolhemos encerrar este trabalho apoiados na narrativa da participante Q1, pois entendemos expressar que a educação e a consequente participação ativa do usuário em todo o processo, desde a escolha e durante o uso, sejam elementos norteadores para a eficiência dos recursos e serviços de Tecnologia Assistiva para a vida das pessoas com deficiência. Nota-se o destaque dado a importância da participação do usuário nos processos de TA. A narrativa evidencia a necessidade do estabelecimento de parcerias entre o usuário, profissionais e familiares quanto às indicações e escolhas necessárias, pois de fato quem vive a deficiência pode melhor indicar aquilo que os cabe frente aos limites impostos pelo ambiente social que compartilham. Tal reflexão, entendemos necessária, em tempos onde as políticas públicas debatem dão ênfase a temas como: inclusão, deficiência e Tecnologia Assistiva.

Refletirmos uma nova e diferente forma de ver e compreender a pessoa com deficiência e a sociedade em que vivemos é importante para que juntos e sob a "orientação das vozes" dessas pessoas possamos reorganizar as escolas, os serviços de saúde, mas principalmente, a oferta de serviços e recursos de Tecnologia Assistiva. Os elementos que buscamos estabelecer entre estes dois campos - Tecnologia Assistiva e Modelo Social - parecem apontar para importantes relações que podem e muito contribuir com a necessária reformulação dos serviços ofertados para os usuários e das produções da indústria de recursos de Tecnologia Assistiva que em muitos casos desconsideram a participação do usuário, moldando recursos para determinadas deficiências como se não houvesse particularidades e singularidades mesmo quando se tratando de um mesmo diagnóstico.

Diante de tudo que aqui discutimos, acreditamos que esses recursos devem ser confeccionados, ou se não forem, que sejam customizados tendo a voz do usuário como foco, pois somente eles são capazes de elencar aspectos relevantes sobre a experiência da deficiência. 
Não é mais possível aceitar que falem da/pela pessoa com deficiência, das suas necessidades, desejos e vontades, pois, infelizmente, ainda são vistas em muitos casos como incapazes de falar por si, quanto mais escolher recursos e serviços de TA que melhor se adéquam as necessidades corporais e individuais. As narrativas dos participantes parecem evidenciar que ainda há profissionais para os quais a possibilidade de parceria com o usuário é inimaginada e o respeito as particularidades não passam de aspectos secundários.

É importante registrar os limites que se apresentaram durante a realização da análise proposta. A coleta de dados se pautou em questionários enviados on-line, e por isso participantes e pesquisadora não estabeleceram um momento de interlocução, o que pode ser entendido como negativo. Talvez por este motivo alguns dados e elementos ficaram implícitos ou não expressos pelos participantes. Não estamos em hipótese alguma descaracterizando as "vozes" que protagonizaram esta análise, sem as narrativas coletadas esta pesquisa não teria sido possível. Acreditamos que este trabalho e outros que apontem na mesma perspectiva podem contribuir e apontar possíveis mudanças no campo da Tecnologia Assistiva.

Portanto, as narrativas dos participantes e autores com que dialogamos apontaram que as "vozes" das pessoas com deficiência devem ser consideradas. Entendemos que os estudos do modelo social da deficiência possam se constituir num importante argumento teórico, social e político capaz de sustentar as reflexões necessárias frente a educação do usuário de Tecnologia Assistiva, para que este torne-se cada vez mais capacitados a fim de que possam tomar decisões responsáveis e reflexivas acerca da intervenção que os recursos e serviços de TA possam exercer em suas vidas.

Encerramos com a certeza de que a sociedade já deu importantes passos acerca da referida tecnologia, da concepção de pessoa com deficiência e sobre inclusão. Porém, outros muitos precisam ser dados, em especial, na busca de que mais e mais usuários finais de TA possam responder à questão inicial deste trabalho: participar por que e para que?

Notas

1 Segundo o Manual Educação em tecnologias de apoio para utilizadores finais: linhas de orientação para formadores (1999 a) "para evitar que termos como decisor ou parceria se transformem em lugares-comuns, desprovidos de qualquer implicação tangível, é importante conceder aos utilizadores finais a possibilidade educacional de se tornarem consumidores informados, exigentes e responsáveis em matéria de TA" (EUSTAT, 1999 a, p. 8).

2 Tecnologia Assistiva ou TA, utilizada no Brasil os sinônimos: Ajudas Técnicas.

$3 \mathrm{O}$ instrumentalismo é o entendimento moderno e padrão adotado perante a tecnologia. Aqui a mesma é entendida como uma ferramenta ou instrumento humano que serve para a satisfação das necessidades dos mesmos (FEENBERG, 2010).

\section{Referências Bibliográficas}

BERSCH, R. de C. R. Introdução à Tecnologia Assistiva. 2005.

BERSCH, R. de C. R. Tecnologia Assistiva: Introdução e aplicações na educação. Centro Especializado em desenvolvimento Infantil. Porto Alegre, 2006.

BERSCH , R. de C. R. Design de um serviço de Tecnologia Assistiva em escolas públicas. 2009. 231 folhas. (Dissertação de Mestrado), Universidade Federal do Rio Grande do Sul, Porto Alegre, RS, Brasil, 2009 .

BRASIL. Portaria número 142, de 16 de novembro de 2006.

BRASIL. Ministério da Educação. Portaria Normativa Número 14, de 24 de abril de 2007

BRASIL. Secretaria Especial dos Direitos Humanos da Presidência da República. Ata da Reunião V do Comitê de Ajudas Técnicas. 2007 a. 
BRASIL. Secretaria Especial dos Direitos Humanos da Presidência da República. Ata da Reunião VII do Comitê de Ajudas Técnicas. 2007 b.

BRASIL. Ministério da Educação. Secretaria de Educação Especial. Política Nacional de Educação Especial na Perspectiva da Educação Inclusiva. Brasília: MEC/SEESP, 2008.

BRASIL. Subsecretaria Nacional de Promoção dos Direitos da Pessoa com Deficiência. Comitê de Ajudas Técnicas. Tecnologia Assistiva. Brasília: CORDE, 2009.

CAIADO, Kátia Regina Moreno. Aluno deficiente visual na escola: lembranças e depoimentos.

Campinas: Autores Associados, 2003. 150 p.

DINIZ, D. O que é deficiência? São Paulo: Editora Brasiliense, 2007.

EUSTAT. Educação em tecnologias de apoio para utilizadores finais: linhas de orientação para formadores, 1999 a.

EUSTAT. Vamos a isso! Manual para usuário de tecnologia de reabilitação, 1999 b.

ESTADOS UNIDOS DA AMÉRICA. (1988). Public Law 100-407, 19 de agosto de 1988.

GALIAZZI, Maria do Carmo e MORAES, Roque. Análise Textual Discursiva. $2^{\text {a }}$ Edição. Ijuí: Editora Unijuí, 2011. 223 p.

GALVÃO FILHO, T. A. Tecnologia Assistiva para uma escola inclusiva [recurso eletrônico]: apropriação, demanda e perspectivas. 2009. (Tese de Doutorado), Universidade Federal da Bahia, Bahia, Brasil.

GALVÃO FILHO, T. A. A Tecnologia Assistiva: de que se trata?. In: MACHADO, G. J. C. e SOBRAL, M. N. Conexões: educação, comunicação, inclusão e interculturalidade. $1^{\text {a }}$ ed. Porto Alegre: Redes Editora, 2009, p. 207-235.

INTERNATIONAL STANDARD. Assistive products for persons with disability Classification and terminology. ISO 9999: 2011.

MARTINS, B. S.; FONTES, F., HESPANHA, P. \& BERG, A. A emancipação dos estudos da deficiência. Revista Crítica de Ciências Sociais [Online], 98, 2012.

NEDER, R. T. (Org). Andrew Feenberg: racionalização democrática, poder e tecnologia. Brasília: Observatório do Movimento pela tecnologia Social na América Latina/ Centro de Desenvolvimento Sustentável - CDS, 2010.

ORGANIZAÇÃO MUNDIAL DA SAÚDE. Classificação Internacional da funcionalidade, incapacidade e saúde. Versão aprovada pela Quinquagésima Quarta Assembleia Mundial de Saúde, 2001.

PALACIOS, J. El modelo social de discapacidad: orígenes, caracterización y plasmación en la Convención Internacional sobre los Derechos de las Personas con Discapacidad. Grupo Editorial Cinca: 2008.

WILLIAMS, John M. The evolution of at: a long night's Journey into Day. News and Notes. Family Center on Tecnology and Desability, Issue 72, 2008. 